\title{
Aviation in Focus
}

http://revistaseletronicas.pucrs.br/ojs/index.php/aviation

\section{A história por trás da foto}

\section{The story behind the photo}

\author{
Luiz Felipe B. de Barros ${ }^{1}$ \\ ${ }^{1}$ Doutor em Desenvolvimento Regional. Autor do livro Asas do Passado.<lfbb777@gmail.com>.
}

\begin{abstract}
RESUMO
Este artigo, intitulado "A história por trás da foto", tem por objetivo resgatar uma passagem singular e esquecida da aviação comercial brasileira, especialmente nas décadas de 1930 e 1940 . Utiliza-se o método monográfico e bibliográfico para, a partir da análise detalhada de uma fotografia sem qualquer relevância, descortinar e revelar a forte influência germânica na América do Sul. Mostra-se os reflexos da cultura germânica, principalmente no modal aéreo, bem como as particularidades das relações Brasil-Alemanha-Brasil após a Primeira Guerra Mundial.
\end{abstract}

PALAVRAS-CHAVE: história da aviação; fotografia; aviões.

\section{ABSTRACT}

This article, entitled "The story behind the photo", aims to examine a unique and forgotten period from Brazilian commercial aviation, principally from the decades of the 1930s and 1940s. The monographic and bibliographic method attempts, from a detailed analysis of the photograph, to discover and reveal the strong Germanic influence in South America. It shows the effects of the German culture, especially on air transportation, as well as the characteristics of the Brazil-Germany-Brazil relationship after the First World War.

KEYWORDS: history of aviation; photography; aircraft.

Pontifical Catholic University of Rio Grande do Sul Porto Alegre, RS, Brazil

Editor

Thaís Russomano

Microgravity Centre PUCRS, Brazil

Executive Editor

Rafael Reimann Baptista

Faculdade de Educação Física e Ciências do Desporto, PUCRS, Brazil

e-ISSN: $2179-703 X$
Corresponding Author:

Luiz Felipe B. de Barros

<lfbb777@gmail.com>

Received: May 25, 2016 Accepted: May 27, 2016

(C) 2016 EDIPUCRS 


\section{Introdução}

Em abril de 2000, após 27 anos frequentando o Aeroporto Internacional Salgado Filho, em Porto Alegre, deparo-me com um desafio proposto pelos supervisores da Infraero (Empresa Brasileira de Infraestrutura Aeroportuária). Descobrir as características de uma foto de grande tamanho (Foto 1), que ilustra uma das paredes da sua sala, sendo que a mesma não dispunha de referência alguma.

Para isso, recorri às fontes que estavam ao meu alcance: Aldo Pereira, em seu livro "Breve história da aviação comercial brasileira", Guia do Deutsches Museum de Munique; "História da Deutsche Lufthansa". Publicações da Lufthansa e informações do Sr. Harro Fouquet (Conselheiro de Administração da Varig), Martin Bernsmüller (expert e detentor do maior acervo fotográfico da aviação brasileira), Carlos Ari César Germano da Silva (piloto e historiador), Günther Spieveck, antigo chefe do setor de motores da Varig, entre outros.

\section{Expancionismo germânico na América do Sul}

Após a derrota da Alemanha na Primeira Guerra Mundial, o Tratado de Versalhes impôs sérias restrições aos alemães, principalmente no seu desenvolvimento bélico-militar-aeronáutico.
O governo alemão, entretanto, arrumou subterfúgios e desenvolveu internamente a difusão em larga escala de planadores e o incremento significativo da formação de pilotos. Externamente, enviava seus pilotos e mecânicos para serem formados e treinados na Rússia, China, Itália e Chile.

Visando interesses dos alemães de expansionismo territorial, mercadológico na venda de aviões e material, e de estudar e implementar o tráfego aéreo na América Central (Sociedade Colombiana Alemana Transportes Aereos - SCADTA - fundada em 1919) e do Sul, foi fundado o consórcio aéreo Condor Syndikat (com sede em Berlim, 1924) pelo piloto-aviador e engenheiro alemão Fritz Hammer e o industrial austríaco Dr. Peter von Bauer. Depois da fundação da Lufthansa em 1926, o Condor Syndikat - que ainda não era empresa de transporte aéreo no Brasil - recebeu do governo brasileiro a autorização especial por um ano para estabelecer tráfego aéreo entre Rio de Janeiro e a cidade de Rio Grande, com escalas, e da cidade de Rio Grande para Pelotas e Porto Alegre.

Não se pretende polemizar sobre qual a empresa de aviação foi pioneira no país, mas os dados mostram que o transporte aéreo iniciou-se no Rio Grande do Sul, em 1927, com o Condor Syndikat, o qual foi formado na Alemanha com o propósito de promover a venda alémmar, de avião comercial alemão, etc. Tal informação é corroborada por Pereira (1987). Segundo ele, a pioneira da aviação comercial brasileira foi a empresa alemã

Foto 1. Focke-Wulf FW 200 'Arumani' - PP-CBJ no aeroporto São João, atualmente aeroporto Salgado Filho

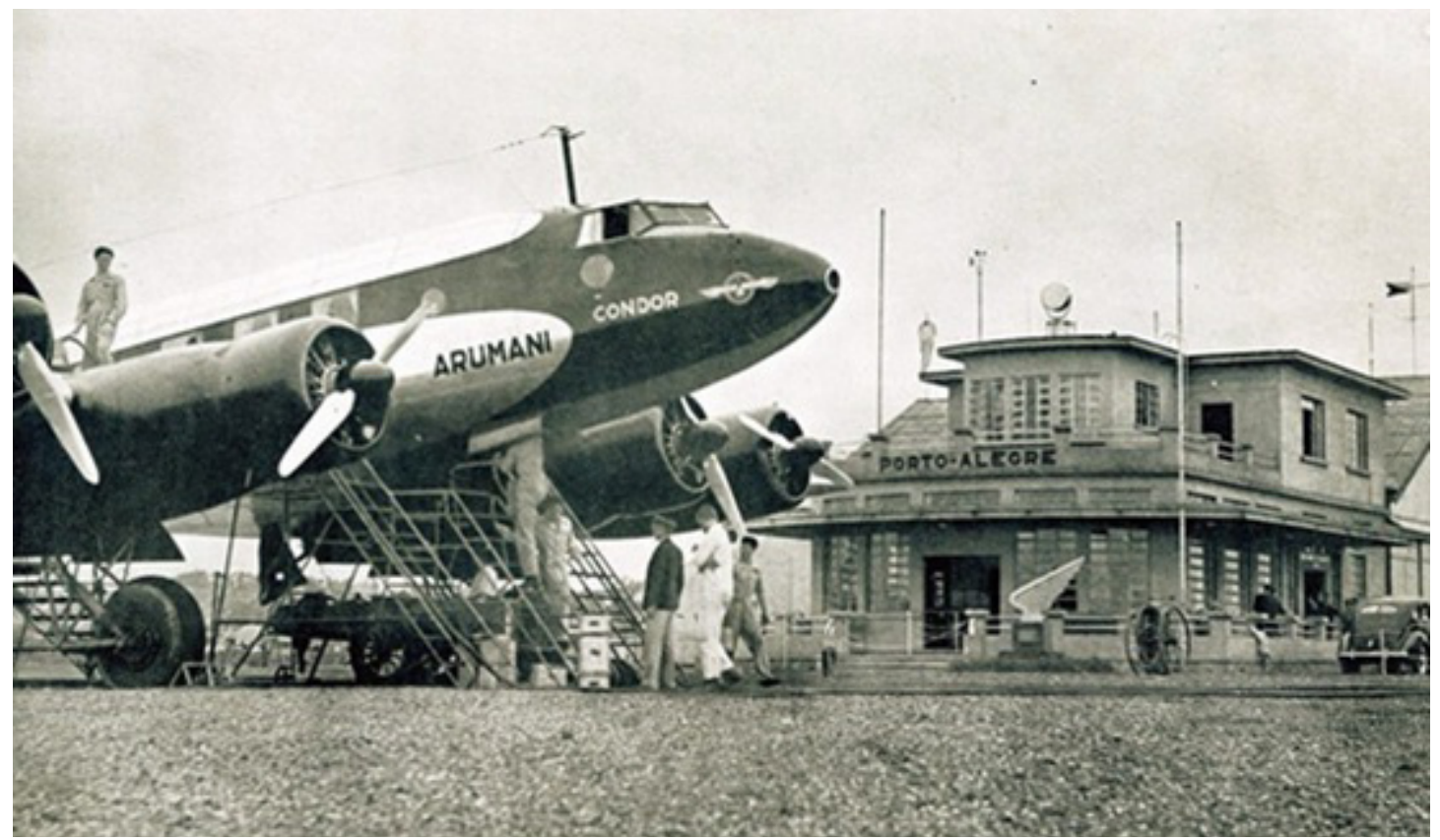

Fonte: SPALDING, Walter (1940). 
Condor Syndikat, que atuava na promoção de vendas de material aeronáutico e de conhecimentos correlatos (PEREIRA, 1987, p. 45):

O Syndicato Condor e a Varig eram pequenos ramos da indústria e dos empresários alemães, enorme árvore que estendia seus ramos pelo mundo afora, pois organizara empresas consumidoras de material aeronáutico em três continentes.

De acordo com Davies (1983), o Syndikat comprou dois hidroaviões Dornier Wal, batizados de Atlantico e o Pacífico, nomes que demonstravam a confiança que caracterizava, na época, o empreendimento alemão de linhas comerciais. Isso ocorreu apesar da deficiência de provisões do Tratado de Versalhes, que restringiu o poder de qualquer aeronave alemã a um único motor e limitou sua produção.

A primeira reunião para discutir a criação da nova empresa - Sociedade Anonyma Empreza de Viação Aérea Riograndense - Varig - aconteceu em 1으 de abril de 1927, na Associação Comercial de Porto Alegre, o que evidencia os interesses dos empresários e comerciantes na criação da empresa e nos serviços de transporte aéreo demandados por eles. Segundo enciclopédia do IBGE publicada em 1959, o capital inicial da empresa foi 1.000 contos de réis divididos em 5 mil ações nominativas de 200 mil réis cada uma, tendo sido subscrito por um total de 550 acionistas, principalmente dos municípios de Porto Alegre, Pelotas, Cachoeira do Sul e Novo Hamburgo. Vinte e um por cento das ações da nova empresa pertenceriam a Condor Syndikat. Em troca, a companhia alemã cedeu uma aeronave Dornier Do J Wal (Atlantico). No dia 07 de maio de 1927, a assembleia dos acionistas decidiu pela fundação da "primeira companhia aérea nacional", a S.A Empresa de Viação Aérea Riograndense, a Varig, com sede em Porto Alegre. Um mês após sua fundação, em 10 de junho de 1927, a Varig recebeu permissão oficial para estabelecer tráfego aéreo em território nacional.

Em maio de 1928, a Condor Syndikat apresentou proposta de fusão com a Varig, mas três anos depois retirou-se da empresa, recebendo de volta os aviões cedidos para realizarem, até então, operações conjuntas. Com isso, a Varig se tornou uma "empresa de avião sem aviões" (PEREIRA, 1987, p. 52).

É importante ressaltar que o início das operações da Condor/Varig deu-se em Rio Grande, Pelotas e Porto Alegre, municípios com maior expressão econômica no Rio Grande do Sul. Como praticamente não havia infraestrutura aeroportuária no Estado sulino, as referidas empresas optaram, então, pela utilização de hidroaviões, com pousos de decolagens às margens do rio Guaíba, em Porto Alegre, e do rio São Gonçalo, em Pelotas. Em Rio Grande, as operações aconteciam nas águas que corriam do estuário, que é o Guaíba, através da Lagoa dos Patos, até a barra de Rio Grande. Referente à relevância desses municípios, Pesavento (1985) observa que, nesse período, as maiores empresas concentravam-se em Porto Alegre, Rio Grande, Pelotas e nos municípios mais populosos da zona colonial, especialmente Caixas do Sul e São Leopoldo.

No início das operações da Condor, e posteriormente da Varig, o avião utilizado era um hidroavião Dornier Do J Wal, aparelho que pousava e decolava em água, uma vez que não existia infraestrutura aeroportuária adequada. Viégas (1989) afirma que, depois de 1930, o governo desenvolveu uma política de uso do avião como instrumento de integração nacional, mas só entre 1934 e 1938 foram construídos mais de 300 campos de pouso no interior do país. As empresas optavam por hidroaviões, por falta de campo de pouso ao longo das linhas em que operavam.

$\mathrm{O}$ primeiro voo comercial foi executado em 03 de fevereiro de 1927 entre Porto Alegre-Pelotas-Rio Grande, seguindo de 66 voos regulares realizados na "Linha da Lagoa" entre 22 de fevereiro e 15 de junho. Em julho de 1927, o Condor Syndikat iniciou o processo de liquidação. Em 02 de dezembro de 1927 foi fundado no Rio de Janeiro o Syndicato Condor Ltda., agora como empresa brasileira, representando os interesses da Lufthansa na América do Sul. A empresa aérea estatal alemã era a arma dos interesses alemães, e o Syndicato Condor, o seu braço fortemente estabelecido no Brasil.

A Condor, com seu programa de estabelecimento de linhas nacionais e de transporte de mala postal oriunda da Europa até o Chile, além da linha regular Rio-Porto Alegre-Buenos Aires, com escala em Montevidéu (1935), se estabelecia fortemente no cenário da América Latina.

Em junho de 1939, a Lufthansa enviava para a sua parceira no Brasil o primeiro quadrimotor Focke-Wulf FW 200. O voo transatlântico coube aos pilotos da Condor, Henke e Schuster. Esta aeronave tinha ainda o nome da proprietária alemã e o nome de batismo Abaitará, sendo que, posteriormente, o prefixo designado foi PP-CBI (Fotos 2 e 3).

Logo em seguida, mais precisamente em 29 de julho de 1939, o legendário piloto da Condor comandante Rudolf Cramer von Clausbruch, decolou de Berlim, com escalas em Sevilha (Espanha), Bathurst (África), Natal e Rio de Janeiro, no segundo FW 200, este intitulado de Arumani, cujo prefixo registrado após foi PP-CBJ (Foto 4). 
Foto 2. Focke-Wulf FW 200 'Abaitará', PP-CBI, no aeroporto Santos Dumont - RJ

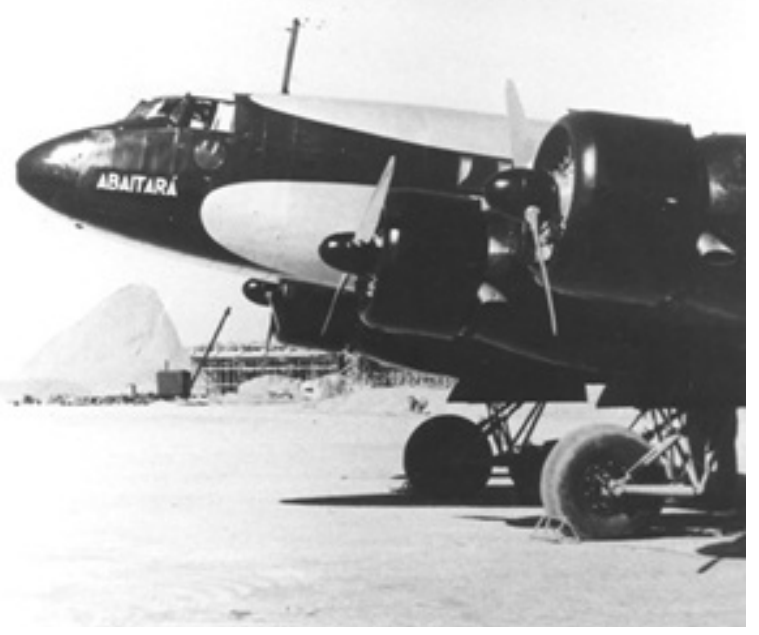

Fonte: Acervo pessoal Martin Bernsmuller.

Foto 3. Quadrimotor Focke-Wulf FW 200 'Abaitará', PP-CBI. Embarque de passageiros da empresa aérea Cruzeiro do Sul

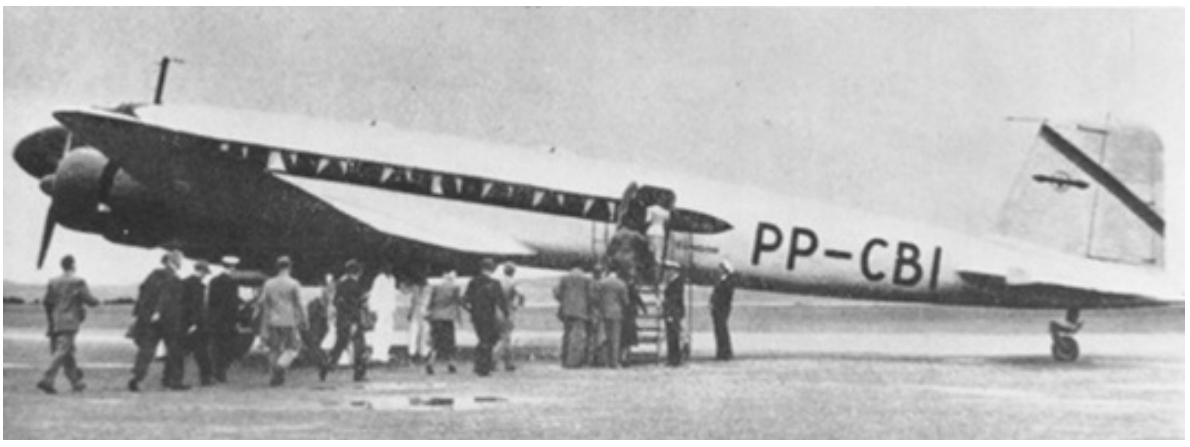

Fonte: Acervo pessoal Martin Bernsmuller.

Foto 4. Focke-Wulf FW 200 'Arumani', ainda com o nome da Lufthansa - Rio de Janeiro, 1939

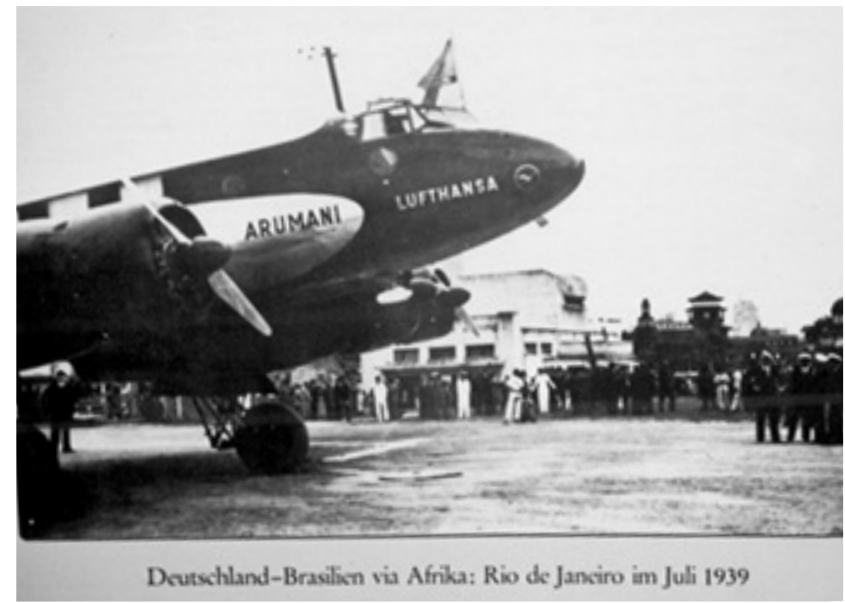

Fonte: DEUTSCHES MUSEUM (2000).
Eram os únicos quadrimotores comerciais terrestres nas Américas, os quais iriam proporcionar expressiva vantagem competitiva a Condor. Os quadrimotores da aviação comercial norte-americanos eram hidroaviões.

Mas, em 19 de agosto de 1941, o nome Syndicato Condor Limitada foi substituído pelo de Serviços Aéreos Condor Limitada, em cumprimento à exigência legal que reservava a denominação Sindicato à organização de classe, conforme determinação do então presidente da República, Getúlio Vargas.

Por pressão dos E.U.A e beligerâncias no litoral brasileiro envolvendo submarinos alemães e embarcações brasileiras, o então Ministro das Relações Exteriores, Sr. Osvaldo Aranha, suspendeu os fornecimentos de gasolina e de outros produtos essenciais à atividade da Condor.

Em janeiro de 1942, a Condor foi nacionalizada. Precisamente um ano depois, prosseguindo na política de apagar qualquer vestígio de sua origem alemã, a Condor teve seu nome trocado pelo de Serviços Aéreos Cruzeiro do Sul Ltda.

Os quadrimotores FockeWulf FW 200 continuaram sendo operados na linha Rio (Santos Dumont)-Buenos Aires, quando em 07 de março de 1947 o FW 200 Abaitará PP. CBI, estacionado no aeroporto Santos Dumont, foi abalroado por um Douglas C-47 da Panair do Brasil. O outro FW 200 Arumani PP-CBJ ficou ativo até meados do ano de 1948 quando, com seu companheiro levemente danificado, foi vendido a um comprador de ferro velho pela Cruzeiro do Sul.

\section{Características técnicas}

O quadrimotor alemão FW 200-A demonstrou as suas possibilidades de voo em grandes distâncias e notabilizou-se quando, em agosto de 1938, um aparelho, especialmente equipado com tanques de combustível suplementares, ligou Berlim (Tempelhof) a Nova York (Floyd Bennet Field), nonstop, numa distância de $6.371 \mathrm{~km}$ em 24 horas e 26 minutos de voo; sendo o regresso e com ventos a favor em 19 horas e 55 minutos.

Por ocasião da eclosão da Segunda Guerra Mundial, o Focke-Wulf FW 200 Condor, somente 16 unidades foram produzidas para uso civil, enquanto outras 263 foram fabricadas em versões militares. Houve 
adaptações para a incumbência de reconhecimento marítimo de grande raio de ação e tornou-se utilíssimo na interceptação dos comboios que rumavam para a Inglaterra e União Soviética. As suas assimilações eram transmitidas aos submarinos em ação de caça na zona. Todavia, quando os comboios começaram a ser escoltados por aviões de caça, os FW 200 foram restituídos à sua antiga função de transporte. Também eram usados no transporte pessoal do Adolf Hitler, em um modelo adaptado para esse fim.

Foto 5. Focke-Wulf FW 200 'Condor', versão militar

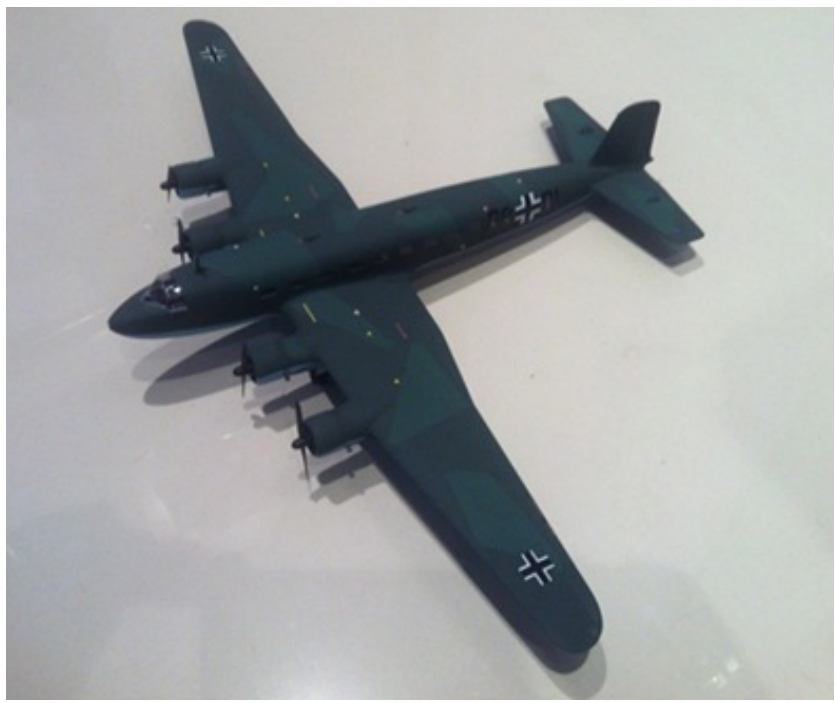

Fonte: Coleção aeromodelo Luiz Felipe Barros.

Foto 6. Focke-Wulf FW 200 'Condor', versão militar

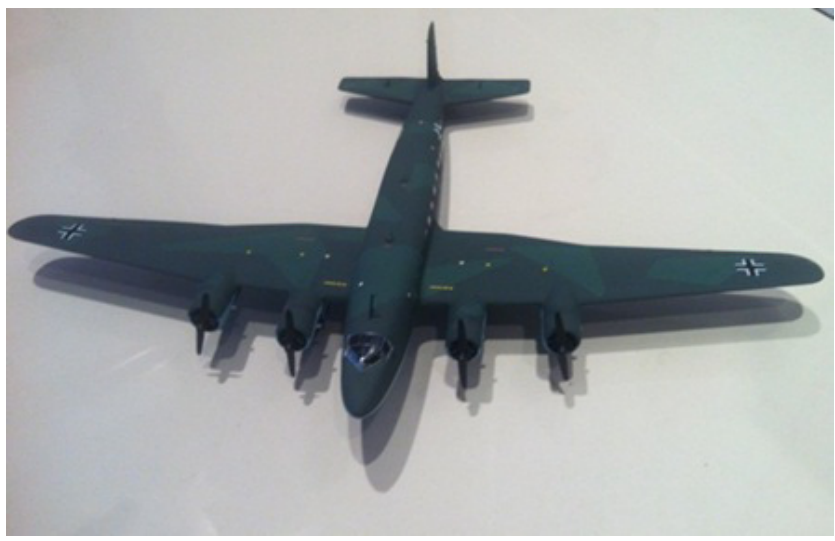

Fonte: Coleção aeromodelo Luiz Felipe Barros.

O FW 200 Condor foi desenhado em 1936 na versão civil. Era um quadrimotor a pistão, monoplano, asa baixa, estrutura metálica. Trem de pouso escamoteável com rodas simples. Bequilha de roda simples (tail-wheel) também escamoteável.

Os dois FW 200 que vieram para o Brasil, tinham motores Pratt and Whitney-Hornet S1EG de $875 \mathrm{HP}$ cada, radial de 9 cilindros, refrigerado a ar; hélices de 2 pás e passo variável; envergadura de 33 metros; comprimento $23 \mathrm{~m}$ e $85 \mathrm{~cm}$; asa de $120 \mathrm{~m}^{2}$; altura de $6 \mathrm{~m}$; peso máx. de decolagem $14.600 \mathrm{~kg}$; velocidade de cruzeiro a $10.000 \mathrm{ft}$ de $325 \mathrm{~km} /$ hora e máxima de $370 \mathrm{~km} /$ hora; teto de serviço de $21.980 \mathrm{ft}$; alcance standard de $1.250 \mathrm{~km}$; capacidade de 26 passageiros, sendo que nove na dianteira (classe preferencial) e dezessete na traseira; quatro tripulantes técnicos.

Faz-se mister uma observação: os FW 200 na versão militar eram equipados normalmente com motores BMW $132 \mathrm{G}$ de $720 \mathrm{HP}$ cada. Mas, também foram utilizados motores mais potentes. Nesses casos, os desempenhos eram diferentes do apresentado.

Existia uma coincidência no nome Condor pintado nos dois FW 200 da Condor. Além do nome da empresa operadora chamar-se Condor, o nome de batismo dado pelo fabricante do avião alemão também era Condor.

Os mesmos também continham em sua fuselagem os nomes Abaitará e Arumani. O responsável por esses nomes foi Frederico Hoepken. Serviu na aviação naval da Alemanha na Primeira Guerra Mundial, como piloto aviador. Era engenheiro civil, profissão exercida no início da década de 20, vindo ao Brasil a trabalho. Ingressou na Condor logo após a sua fundação, tendo exercido a direção técnica até 1942. Passou se interessar pelos índios brasileiros viajando pelo interior do Mato Grosso. No começo, os aviões da Condor tinham nomes diversos (Ypiranga, Santos Dumont, Bartholomeu de Gusmão, Flamengo, Blumenau, Potyguar, Jangadeiro, etc.). Depois foram batizados com nomes indígenas como: Anhangá, Jacy, Aracy, Uirapuru, Iarussu, Pagé, Abaitará, Arumani, e tantos outros. Os nomes indígenas foram dados por sua recomendação e escolha a Lufthansa.

\section{Considerações finais}

Em relação à foto que gerou essa pequena história, foi tirada pelo fotógrafo W. Hoffmann Harnisch Filho, entre o final de 1939 e no início de 1940, publicada pela prefeitura municipal de Porto Alegre em uma edição do departamento central dos festejos do bicentenário da cidade, com o título de "retrato de uma cidade". Era no aeroporto São João (situado no distrito do mesmo nome), sendo que em julho de 1940, o aeroporto passa a denominar-se Aeroporto de Porto Alegre.

Contudo, o aeroporto tornou-se obsoleto e em 12 de outubro de 1951, pelo Decreto Lei 1457, o Aeroporto de Porto Alegre foi designado de Aeroporto Salgado Filho, em homenagem ao gaúcho Senador Joaquim Pedro Salgado Filho, primeiro Ministro da Aeronáutica (1941 a 1945), grande incentivador da Campanha da Aviação e Indústria Aeronáutica, falecido em 1950. 
A antiga estação de passageiros retratada, encontrase hoje nas dependências da TAP Porto Alegre (TAP Manutenção e Engenharia Brasil S.A.), e a grande asa está localizada próxima ao que ainda resta do Museu Varig, em Porto Alegre.

Graças a magia da lente de W. Hoffmann Harnisch Filho, conseguimos decifrar um pouco da história por trás da foto. Como o poeta Mario Quintana dizia: "O fotógrafo tem a mesma função do poeta: eternizar o momento que passa”.

\section{Referências}

Barros LFB. Asas do passado. Santa Cruz do Sul: EDUNISC; 2012.

Brasil. Lei $\mathrm{n}^{\mathrm{o}}$ 1.457, de 12 de outubro de 1951. Dá nova denominação ao Aeroporto São João, em Porto Alegre, Rio Grande do Sul. Disponível em: <http://www2.camara.leg.br/ legin/fed/lei/1950-1959/lei-1457-12-outubro-1951-362140publicacaooriginal-1-pl.html >. Acesso em: 23 ago. 2001.
Davies REG. Airlines of Latin America since 1919. London: Putnan, 1983.

Deutsches Museum. História da Deutsche Lufthansa. Deutsches Museum Munchen. Disponível em: < http://www.deutschesmuseum.de/>. Acesso em: 22 set. 2000.

IBGE. Instituto Brasileiro de Geografia e Estatística. Enciclopédia dos municípios brasileiros. Rio de Janeiro: IBGE; 1959. v. 33 e 34.

Lira Neto. Getúlio: Do Governo Provisório à ditadura do Estado Novo (1930-1945). 1ำ ed. São Paulo: Companhia das Letras; 2013.

Pereira A. Breve história da aviação comercial brasileira. Rio de Janeiro: Europa; 1987.

Pesavento SJ. História da Indústria sul-rio-grandense. Guaíba: RIOCELL; 1985.

Spalding W (coord.). Porto Alegre, Retrato de uma Cidade. Departamento central dos Festejos do Bicentenário. Porto Alegre: Of. Graf. Da Livraria do Globo; 1940.

Sweeting CG. O Piloto de Hitler - a Vida e a Época de Hans Baur. São Paulo: Jardim dos Livros; 2011.

Viégas JA. Vencendo o Azul: História da indústria e tecnologia aeronáuticas no Brasil. São Paulo: Livraria Duas Cidades; 1989. 